\title{
P304: Conducts following occupational accidents involving exposure to biological material among emergency medical services personnel
}

\author{
MHRS Paiva*, ACD Oliveira, AOD Paula \\ From 2nd International Conference on Prevention and Infection Control (ICPIC 2013) \\ Geneva, Switzerland. 25-28 June 2013
}

\section{Introduction}

The adoption of post-accident conducts can be decisive for minimizing or avoiding the acquisition of diseases as a result of the occupational accident.

\section{Objectives}

The aim was to estimate the prevalence of accidents involving exposure to biological material, post-accident conducts and the undertaking of serological monitoring concerning the possibility of transmission of the AIDS virus and Hepatitis $B$ and $C$ among the Emergency Medical Services professionals in Minas Gerais, Brazil.

\section{Methods}

This descriptive cross-sectional study was undertaken with professionals of the public EMS in the state of Minas Gerais. Data was collected between December 2011 and July 2012, via a structured questionnaire and analyzed by the Statistical Package for Social Science (SPSS). Characterization of population, post-accident conducts and serological monitoring of the affected professional was verified through calculation of absolute and relative frequencies.

\section{Results}

487 workers participated in the study; 124 physicians (25.5\%), 60 nurses (12.3\%), 173 nurse technicians (35.5\%) and 130 drivers (26.7\%). The global prevalence of professionals occupationally involved in biological material accidents was $17.0 \%$ (83/487). However, $33.7 \%$ of these workers referred to more than one accident, totaling 121 exposures to body fluids in this period. It was ascertained that after the accident, $35.5 \%(43 / 121)$ of the cases reported undergoing medical evaluation; for 29.7\% (36/ $121)$ an accident report was issued; for $13.2 \%(16 / 121)$, 9.1\% (11/121) and $10.7 \%(13 / 121)$ the undertaking of serology for Hepatitis B, C and HIV respectively was mentioned, both from departments and personnel. For Hepatitis B it was ascertained that only $4.9 \%$ (6/121) of affected professionals were monitored for one year after the occurrence of exposure to $\mathrm{BM} ; 2.5 \%(03 / 121)$ for Hepatitis $\mathrm{C}$; and $5.8 \%(07 / 121)$ for HIV.

\section{Conclusion}

It is hoped that these results may stimulate discussion about the importance of accident notification and evaluation, and of the monitoring of the affected professional.

\section{Disclosure of interest}

None declared.

Published: 20 June 2013

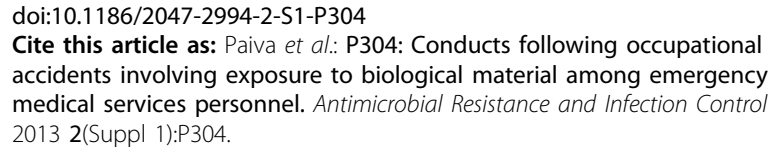

